\title{
A Charge-transfer Phenomenon between 2,3,5,6-Tetrafluoro-7,7,8,8-tetracyano- p-quinodimethane (F4TCNQ) and a Tetrathiafulvalene-based Self-assembled Monolayer Using an Indium-Tin Oxide Electrode
}

\author{
Jin-Sun Kim, ${ }^{a}$ Su-Kyung Lee, Ha-Jin Lee, ${ }^{\dagger}$ and Dong-Youn Noh ${ }^{*}$ \\ Department of Chemistry, Seoul Women's University, Seoul 139-774, Korea. EE-mail: dynoh@swu.ac.kr \\ ${ }^{\dagger}$ Jeonju Center of Korea Basic Science Institute, Jeonju 561-756, Korea \\ Received January 29, 2010, Accepted March 23, 2010
}

Key Words: Charge-transfer, F4TCNQ, EDT-TTF, SAM, ITO

Tetrathiafulvalene (TTF: $\mathrm{C}_{6} \mathrm{H}_{4} \mathrm{~S}_{4}$ ) is a well-known two-electron donor molecule that is electrochemically active, showing two reversible redox cycles at $E_{1 / 2}{ }^{1}=0.33 \mathrm{~V}$ and $E_{1 / 2}{ }^{2}=0.71$ $\mathrm{V}$ (vs SCE). ${ }^{1}$ It reacts with 7,7,8,8-tetracyanoquinodimethane (TCNQ) to form an electrically conductive TTF-TCNQ chargetransfer (CT) complex with metallic conductivity at room temperature. $^{2}$ Thereafter, many kinds of TTF-TCNQ-family CT complexes composed of, for example, ethylenedithio-tetrathiafulvalene (EDT-TTF) and 2,3,5,6-tetrafluoro-7,7,8,8-tetracyanoquinodimethane (F4TCNQ), have followed. ${ }^{3}$ In the early stage, the CT complexes in the form of a single crystal were investigated with respect to their bulk properties such as crystal structure, electrical conductivity, and optical properties. With many techniques such as LB-film, chemical vapor deposition (CVD), and self-assembled monolayers (SAM), having been applied in this research field, the properties of CT complexes with a mono- or multi-layer have been intensively investigated. ${ }^{4-6}$ Among these techniques, it is relatively easy to prepare SAM film and highly promising to construct such molecular architectures on metal and semiconductor surfaces. ${ }^{5}$ For example, a Au surface modified with a dodecanethiol chain with an EDT-TTF functional-group has already been reported. ${ }^{7}$
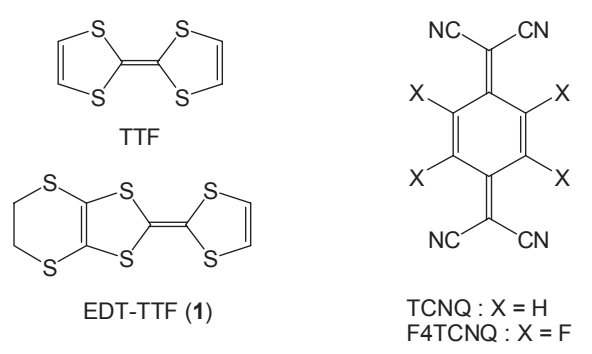

In the current work, a redox-active EDT-TTF group linked to a decanephosphonic acid (compound 5) was synthesized and used for the development of SAM on the surface of an electrically conductive indium-tin oxide (ITO) substrate. This surface-modified ITO (SM-ITO) was used to generate a CT salt with F4TCNQ by boiling, soaking, and electrochemical methods. The formation of the CT complex on the SM-ITO surface was confirmed by micro-Raman spectroscopic measurements, as well as cyclic voltammetry (CV) results.

${ }^{a}$ Present address: Electronic Materials Division, Dongjin Semichem Co., Ltd., Korea.

\section{Experimental Section}

Materials. All synthetic reactions were carried out using dried glassware under an argon atmosphere overnight in an oven at $110{ }^{\circ} \mathrm{C}$. Dichloromethane was dried over $\mathrm{MgSO}_{4}$, and triethyl phosphite $\left(\mathrm{P}(\mathrm{OEt})_{3}\right)$ was distilled prior to use. Tetrahydrofuran (THF) was freshly distilled over sodium benzophenone. Indiumtin oxide (ITO) film-coated glass plates from Samsung Corning Co., Ltd (sheet resistance: $8.5 \pm 1.5 \Omega / \square$, size: $35 \times 10 \mathrm{~mm}^{2}$, transmission: $80.0 \sim 92.0 \%$, flatness $\leq 400 \AA$ ) were used.

Measurements. The reflection-absorption FT-IR spectra of SAM on ITO glass were measured on a Perkin Elmer Spectrum 100 spectrometer equipped with a specular reflectance attachment (PIKE Technol.). The spectroscopic measurements, viz. UV-vis, micro-Raman, FT-IR, FAB-mass and NMR spectroscopies, were carried out as described elsewhere..$^{8-9}$

Cyclic voltammetry $(\mathrm{CV})$ measurements were carried out at room temperature with a $\mathrm{CHI} 620 \mathrm{~A}$ Electrochemical Analyzer ( $\mathrm{CH}$ Instruments Inc.) in $\mathrm{CH}_{2} \mathrm{Cl}_{2}$ solution $(2 \mathrm{~mL})$ containing $0.1 \mathrm{Mn}-\mathrm{Bu}_{4} \mathrm{~N} \cdot \mathrm{PF}_{6}$ as a supporting electrolyte, with a scan rate of $50 \mathrm{mV} \mathrm{s}^{-1}$, the $\mathrm{Ag} / \mathrm{AgCl}($ sat. $3 \mathrm{M} \mathrm{KCl})$ as a reference electrode, Pt-disk $(\phi=2 \mathrm{~mm})$ or ITO glass $\left(A \approx 7 \mathrm{~mm}^{2}\right)$ as a working electrode, and Pt-wire $(\phi=0.3 \mathrm{~mm})$ as a counter electrode. All potentials were referenced to a $\mathrm{Fc} / \mathrm{Fc}^{+}$couple $\left(E_{1 / 2}=0.526 \mathrm{~V}\right)$ unless otherwise noted.

Preparation of compound (3). To a degassed THF solution (40 mL) of compound (2) $)^{1}(420 \mathrm{mg}, 1.1 \mathrm{mmol})$ was added a methanol solution $(3.4 \mathrm{~mL})$ of cesium hydroxide monohydrate (180 mg, $1.1 \mathrm{mmol}$ ) dropwise from an addition funnel over $0.5 \mathrm{~h}$. After stirring for $0.5 \mathrm{~h}, 1,10$-dibromodecane ( $3 \mathrm{~mL}, 12$ eq.) was added to a brown reaction mixture, followed by stirring for an additional $2 \mathrm{~h}$. The light-brown precipitate was filtered off, and the filtrate was dried in vacuo to obtain the dark-red oil. It was purified by column chromatography $\left(\mathrm{SiO}_{2}, \mathrm{CH}_{2} \mathrm{Cl}_{2}: n\right.$-hexane $=$ $1: 1)$, and isolated as a red oil upon concentration. Yield 55\% (330 mg). HR-FAB (m/z): Calcd. for $\mathrm{C}_{18} \mathrm{H}_{25}{ }^{79} \mathrm{Br}_{1} \mathrm{~S}_{7}$ : 543.9185 , Found: 543.9175 (100.0\%), Calcd. for $\mathrm{C}_{18} \mathrm{H}_{25}{ }^{81} \mathrm{Br}_{1} \mathrm{~S}_{7}$ : 545.9164, Found: $545.9183(99.4 \%) .{ }^{1} \mathrm{H}-\mathrm{NMR}\left(500 \mathrm{MHz}, \mathrm{CDCl}_{3}\right) \delta 6.33$ $(1 \mathrm{H}, \mathrm{CH}, \mathrm{s}), 3.41\left(2 \mathrm{H}, \mathrm{CH}_{2}, \mathrm{t}, J=6.87 \mathrm{~Hz}\right), 3.29\left(4 \mathrm{H}, \mathrm{CH}_{2}, \mathrm{~s}\right)$, $2.74\left(2 \mathrm{H}, \mathrm{CH}_{2}, \mathrm{t}, J=7.35 \mathrm{~Hz}\right), 1.86\left(2 \mathrm{H}, \mathrm{CH}_{2}, \mathrm{qn}, J=7.41 \mathrm{~Hz}\right)$, $1.60\left(2 \mathrm{H}, \mathrm{CH}_{2}, \mathrm{qn}, J=7.44 \mathrm{~Hz}\right), 1.40\left(4 \mathrm{H}, \mathrm{CH}_{2}, \mathrm{~m}\right), 1.29(8 \mathrm{H}$, $\mathrm{CH}_{2}$, s). FT-IR $\left(\mathrm{KBr}, \mathrm{cm}^{-1}\right): 3077(=\mathrm{CH}), 2926,2852\left(-\mathrm{CH}_{2}\right.$ $\left.\mathrm{CH}_{2-}\right), 1552(\mathrm{C}=\mathrm{C}), 1462,1434,1413\left(-\mathrm{CH}_{2} \mathrm{~S}-\right), 1287,1259$, 


\section{$1232\left(\mathrm{BrCH}_{2}^{-}\right)$.}

Preparation of compound (4). Compound (3) (270 mg, 0.5 mmol) was dissolved in freshly distilled $\mathrm{P}(\mathrm{OEt})_{3}(7 \mathrm{~mL})$ and refluxed for $3 \mathrm{~h}$ under argon atmosphere. The brown solution was cooled to room temperature and dried in vacuo. The product was then purified by column chromatography $\left(\mathrm{SiO}_{2}\right.$, acetone : diethyl ether $=1: 20)$ as a dark-brown oil. Yield $90 \%(270 \mathrm{mg})$. HR-FAB $(\mathrm{m} / \mathrm{z})$ : Calcd. for $\mathrm{C}_{22} \mathrm{H}_{35} \mathrm{O}_{3} \mathrm{P}_{1} \mathrm{~S}_{7}: 602.0369$, Found: 602.0383. ${ }^{1} \mathrm{H}-\mathrm{NMR}\left(500 \mathrm{MHz}, \mathrm{CDCl}_{3}\right) \delta 6.33(1 \mathrm{H}, \mathrm{CH}, \mathrm{s}), 4.09$ $\left(4 \mathrm{H}, \mathrm{CH}_{2}, \mathrm{~m}\right), 3.28\left(4 \mathrm{H}, \mathrm{CH}_{2}, \mathrm{~s}\right), 2.73\left(2 \mathrm{H}, \mathrm{CH}_{2}, \mathrm{t}, J=7.35 \mathrm{~Hz}\right)$, 1.78-1.68 (2H, $\left.\mathrm{CH}_{2}, \mathrm{~m}\right), 1.61-1.57\left(2 \mathrm{H}, \mathrm{CH}_{2}, \mathrm{~m}\right), 1.43(2 \mathrm{H}$, $\left.\mathrm{CH}_{2}, \mathrm{~m}\right), 1.35\left(4 \mathrm{H}, \mathrm{CH}_{2}, \mathrm{~m}\right), 1.32\left(12 \mathrm{H}, \mathrm{CH}_{2}, \mathrm{~m}\right), 1.17(6 \mathrm{H}$, $\left.\mathrm{CH}_{3}, \mathrm{~m}\right) .{ }^{31} \mathrm{P}-\mathrm{NMR}\left(200 \mathrm{MHz}, \mathrm{CDCl}_{3}\right) \delta 34.00$ (s). FT-IR (KBr, $\left.\mathrm{cm}^{-1}\right)$ : 2980, 2928, $2854\left(-\mathrm{CH}_{2} \mathrm{CH}_{2}-\right), 1713(\mathrm{C}=\mathrm{C}), 1462,1441$, $1415\left(\mathrm{PCH}_{2}-\right), 1362(\mathrm{P}=\mathrm{O}), 1289,1222\left(-\mathrm{CH}_{2}-\right), 1164\left(\mathrm{CH}_{3}\right)$, 1058, 1030, 963 (P-O-C).

Preparation of compound (5). To a $\mathrm{CH}_{2} \mathrm{Cl}_{2}$ solution (4 mL) of compound (4) $(91 \mathrm{mg}, 0.15 \mathrm{mmol})$, triethylamine $(0.58 \mathrm{~mL})$ and bromotrimethylsilane $(0.56 \mathrm{~mL})$ were slowly added from a syringe. During the addition, a white precipitate became evident in the flask. After stirring for $2 \mathrm{~h}$, the solution was concentrated in vacuo, and methanol $(4 \mathrm{~mL})$ was added to the residue, followed by additional stirring for $4 \mathrm{~h}$. The concentrated residue was dissolved in $\mathrm{CH}_{2} \mathrm{Cl}_{2}$ and extracted with de-ionized water. The second extract in $\mathrm{CH}_{2} \mathrm{Cl}_{2}$ was obtained and concentrated as a red-brown oil. ${ }^{10}$ Yield 70\% $(57 \mathrm{mg})$. HR-FAB $(\mathrm{m} / \mathrm{z})$ : Calcd. for $\mathrm{C}_{18} \mathrm{H}_{27} \mathrm{O}_{3} \mathrm{P}_{1} \mathrm{~S}_{7}$ : 545.9743, Found: 545.9736. ${ }^{1} \mathrm{H}-\mathrm{NMR}$ (500 $\left.\mathrm{MHz} \mathrm{CDCl}_{3}\right) \delta 6.33(1 \mathrm{H}, \mathrm{CH}, \mathrm{s}), 3.29\left(4 \mathrm{H}, \mathrm{CH}_{2}, \mathrm{~s}\right), 2.74-2.71$ $\left(2 \mathrm{H}, \mathrm{CH}_{2}, \mathrm{t}, J=7.33 \mathrm{~Hz}\right), 1.63-1.57\left(2 \mathrm{H}, \mathrm{CH}_{2}, \mathrm{~m}\right), 1.35-1.32(4 \mathrm{H}$, $\left.\mathrm{CH}_{2}, \mathrm{~m}\right), 1.25\left(12 \mathrm{H}, \mathrm{CH}_{2}, \mathrm{~s}\right) .{ }^{13} \mathrm{C}-\mathrm{NMR}\left(126 \mathrm{MHz}, \mathrm{CDCl}_{3}\right) \delta$ 118.49, 114.22-114.12, 106.42, 121.74, 30.94, 36.31, 23.06, $8.79,30.45,29.73,29.62,29.44,29.31,28.60 .{ }^{31} \mathrm{P}-\mathrm{NMR}(200$ $\left.\mathrm{MHz} \mathrm{CDCl}_{3}\right) \delta 32.97$ (s). FT-IR (KBr, cm $\left.{ }^{-1}\right): 3014,2929,2855$ $\left(-\mathrm{CH}_{2} \mathrm{CH}_{2}-\right), 1724(\mathrm{C}=\mathrm{C}), 1463\left(-\mathrm{CH}_{2} \mathrm{~S}-\right), 1263,1287(\mathrm{P}=\mathrm{O})$, $1216\left(-\mathrm{CH}_{2}-\right), 1116,930$ (P-O-C), 758 (P-C).

Development of SAM of compound (5) on ITO glass. ITO glass $\left(35 \times 10 \mathrm{~mm}^{2}\right)$ was cleaned with each of TCE, acetone, methanol and de-ionized water by sonication for $10 \mathrm{~min}$, and dried under $\mathrm{N}_{2}$ flow. The ITO glass was then immersed in $1.0 \mathrm{mM}$ $\mathrm{CH}_{2} \mathrm{Cl}_{2}$ solution of compound (5) with sonication for $10 \mathrm{~min}$. The ITO substrate was rinsed three times with $\mathrm{CH}_{2} \mathrm{Cl}_{2}$, and dried by blowing $\mathrm{N}_{2}$ stream over the surface.

Preparation of SAM of compound (5)-F4TCNQ chargetransfer salt. The prepared surface-modified ITO (SM-ITO) glass was refluxed or soaked at room temperature in $10 \mathrm{mM}$ $\mathrm{CH}_{2} \mathrm{Cl}_{2}$ solution of F4TCNQ $(0.1 \mathrm{mM})$ for $1 \mathrm{~h}$. The SM-ITO substrate was then rinsed with absolute ethanol three times and dried by blowing $\mathrm{N}_{2}$ stream over the surface.

\section{Results and Discussion}

Compound (5), which is an EDT-TTF derivative with an n-decylphosphonic acid group, was prepared by a modification of previously reported methods, ${ }^{6,11}$ as illustrated in Scheme 1. The oily compound (5), as well as compounds (3) and (4), was fully characterized by FT-IR, HR-FAB mass and ${ }^{1} \mathrm{H} /{ }^{13} \mathrm{C} /{ }^{31} \mathrm{P}$ NMR spectroscopies. COSY $\left({ }^{1} \mathrm{H}^{-1} \mathrm{H}\right)$ and $\mathrm{HSQC}\left({ }^{13} \mathrm{C}-{ }^{1} \mathrm{H}\right)$ spectra for compound (5) are available in Supporting Informa- tion. The energy-minimized molecular structure of compound (5) shown in Scheme 2 has an almost planar EDT-TTF moiety and normal alkyl chain with all trans-conformation.

The formation of SAM was successfully achieved by the sonication of ITO glass in a $1.0 \mathrm{mM} \mathrm{CH}_{2} \mathrm{Cl}_{2}$ solution of compound (5), following the reported process. ${ }^{8}$ It was confirmed and characterized by reflection-absorption FT-IR spectrum (Fig. 1), in which the normal alkyl chain peaks were observed at $2852 \mathrm{~cm}^{-1}$ for $v_{\text {sym }}\left(\mathrm{CH}_{2}\right)$ and $2920 \mathrm{~cm}^{-1}$ for $v_{\text {antisym }}\left(\mathrm{CH}_{2}\right){ }^{12} \mathrm{~A}$ peak observed at $2951 \mathrm{~cm}^{-1}$ was assigned to the $v\left(\mathrm{CH}_{2}\right)$ of the EDT moiety. ${ }^{13}$ The $\mathrm{CV}$ results of the surface-modified indiumtin oxide (SM-ITO), along with those of UV-vis and AFM measurements, ${ }^{8}$ also indicate good SAM development, as will be discussed below. The driving forces for the formation of SAMs by compound (5) on ITO surface are the packing interactions between neighboring alkane chains and the interaction between phosphonate groups and the indium metal atoms of the surface. ${ }^{14}$

In order to investigate the electron transfer phenomena between the EDT-TTF moiety in SAM and ITO electrode, CV measurements were carried out using SM-ITO as a working electrode in $\mathrm{CH}_{2} \mathrm{Cl}_{2}$ solution containing $0.1 \mathrm{Mn}-\mathrm{Bu}_{4} \mathrm{~N} \cdot \mathrm{PF}_{6}$ as a supporting electrolyte and no redox active species. Two rever-

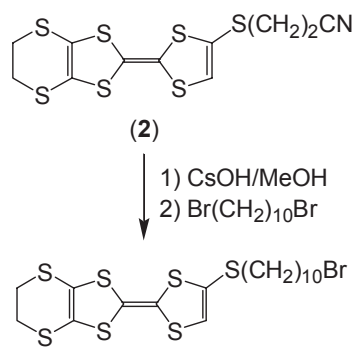

(3) $\mathrm{P}(\mathrm{OEt})_{3}$

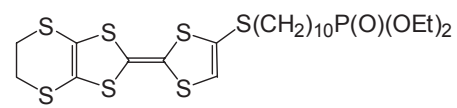

(4)

1) $\mathrm{N}\left(\mathrm{CH}_{2} \mathrm{CH}_{3}\right)_{3}$ 2) $\mathrm{BrSi}\left(\mathrm{CH}_{3}\right)_{3}$

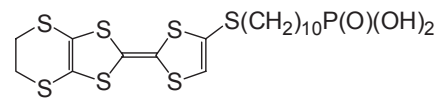

(5)

Scheme 1. Synthesis of EDT-TTF derivatives

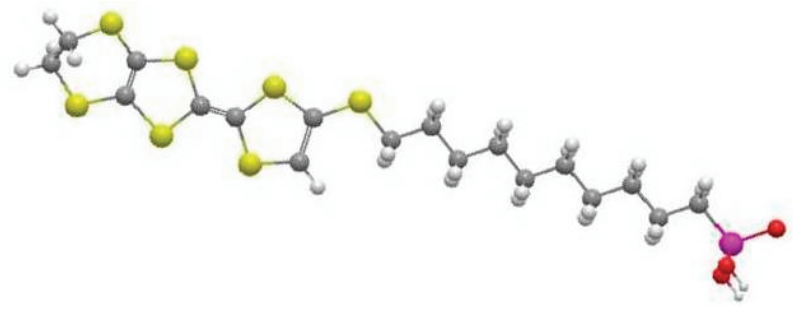

Scheme 2. Energy-minimized molecular structure of compound (5) (Chem. 3D Ultra, ver. 10.0, 2006) 


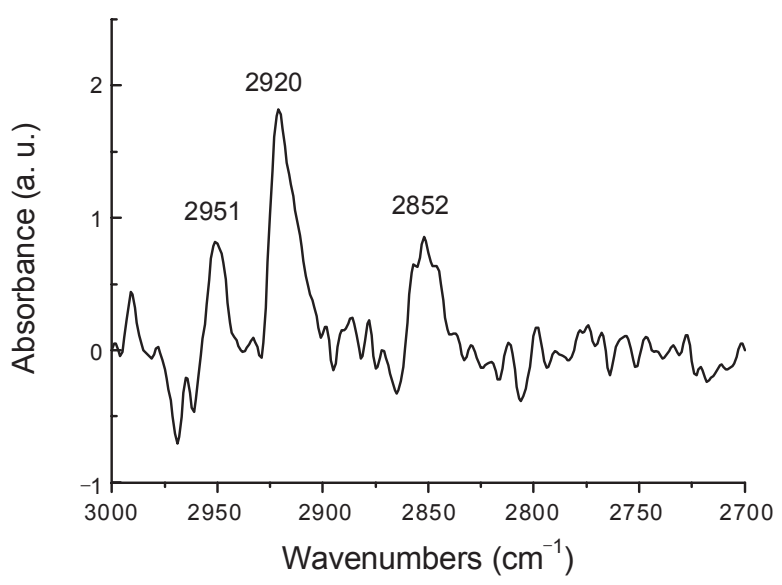

Figure 1. Reflection-absorption FT-IR spectrum (alkyl C-H stretching region) for the self-assembled monolayer of compound (5) on ITO substrate.

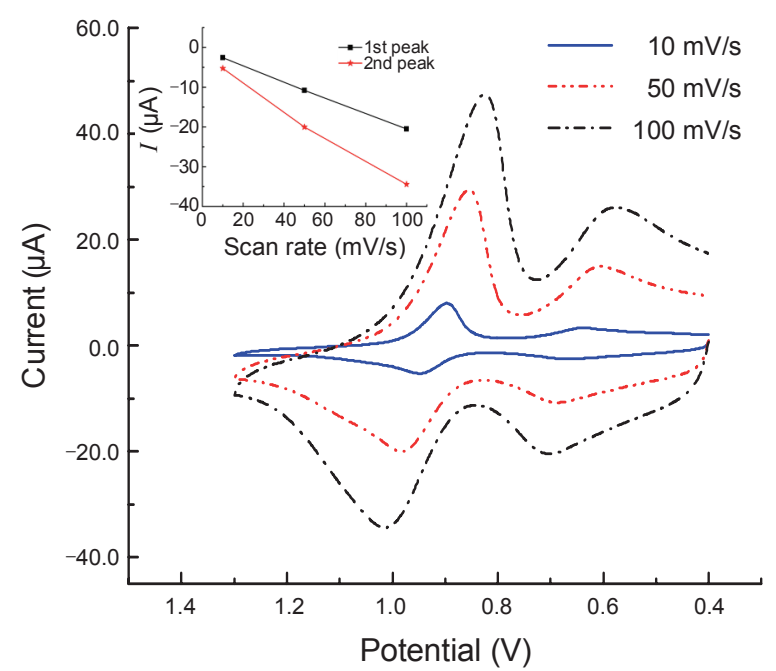

Figure 2. Cyclic voltammograms for the SM-ITO electrode at scan rates of 10,50 , and $100 \mathrm{mV} \mathrm{s}^{-1}$ (Inset: plot of peak current $(I) v s$. scan rate).

sible redox cycles $\left(E_{1 / 2}{ }^{1}=0.646 \mathrm{~V}\right.$ and $E_{1 / 2}{ }^{2}=0.919 \mathrm{~V} v s$. $\mathrm{Ag} / \mathrm{AgCl}$ with $50 \mathrm{mV} \mathrm{s}^{-1}$ scan rate) were shown, as many EDT-TTF derivatives do. ${ }^{1}$ As the scan rate increases, the peak currents of two reversible cycles corresponding to [EDT-TTF $]^{+/ / o}$ and $[\mathrm{EDT}-\mathrm{TTF}]^{2+/ \bullet+}$ processes also increased together with increases in anodic potential $\left(E_{\mathrm{pa}}\right)$, as shown in Fig. 2. The plot of peak current $(I)$ with respect to the scan rate demonstrates the proportional relationship (Fig. 2(inset)), indicating a 'surface wave' response, similar to that shown in previous reports about EDT-TTF $\left(\mathrm{SC}_{11} \mathrm{H}_{22} \mathrm{SH}\right)_{2}{ }^{13 \mathrm{a}}$ and TTF- $\mathrm{CH}_{2} \mathrm{SH}^{15} \mathrm{SAMs}$ on a $\mathrm{Au}(111)$ substrate.

The SM-ITO glass was soaked or boiled in a $10 \mathrm{mM} \mathrm{CH}_{2} \mathrm{Cl}_{2}$ solution of F4TCNQ for $1 \mathrm{~h}$, and then used as a working electrode for $\mathrm{CV}$ measurements in $\mathrm{CH}_{2} \mathrm{Cl}_{2}$ solution. As shown in Fig. 3A, when the SM-ITO glass boiled in F4TCNQ solution was used as a working electrode, two redox cycles of the EDT-TTF moiety in SAM were obscure. It can be supposed that the EDT-TTF moiety (a good electron donor) forms a chargetransfer (CT) complex on the surface of SAM with a good electron acceptor (F4TCNQ) upon boiling. As this CT complex
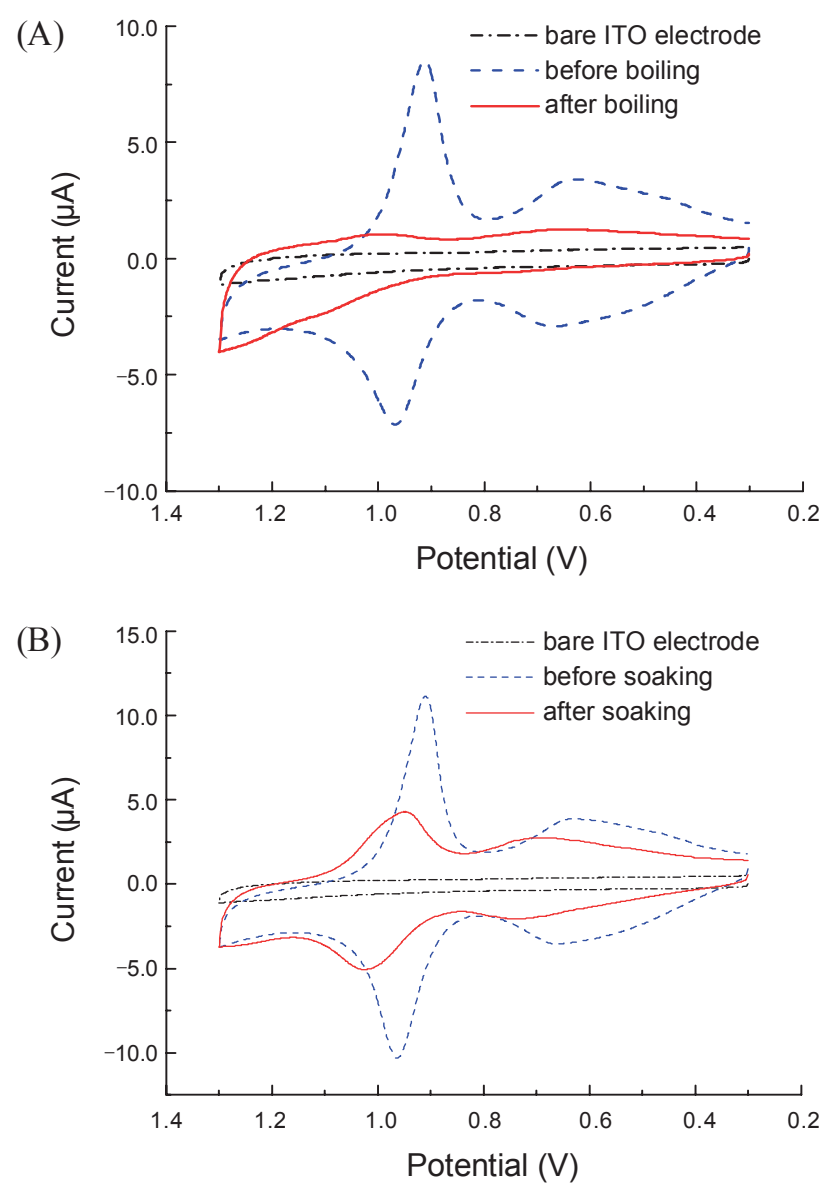

Figure 3. Cyclic voltammograms using the SM-ITO electrode before and after boiling (A) or soaking (B) in a $\mathrm{CH}_{2} \mathrm{Cl}_{2}$ solution of F4TCNQ.

would be highly stable, enough to survive under the applied potential during the $\mathrm{CV}$ measurement, the obvious redox cycle was not observed. It is noteworthy that the CT complex seems to have been formed, as well, even when the SM-ITO glass was soaked in F4TCNQ solution at room temperature. It can be reasoned from Fig. 3B that the peak currents obtained using the soaked SM-ITO electrode are still present, possibly due to a partial formation of CT complex on the surface of SM-ITO electrode by soaking. The micro-Raman spectra of these two cases indicate the formation of a $\mathrm{CT}$ salt on the surface of SMITO electrode as shown in Fig. 4: The $\mathrm{C}=\mathrm{C}$ ring stretching $\left(v_{2}\right.$ $\left.1665 \mathrm{~cm}^{-1}\right)$ and external stretching $\left(v_{3} 1456 \mathrm{~cm}^{-1}\right)$ vibrations observed for a neutral F4TCNQ compound, shift to 1616 and $1340 \mathrm{~cm}^{-1}$ for a boiled SM-ITO, and 1609 and $1338 \mathrm{~cm}^{-1}$ for a soaked SM-ITO. These observations imply the formation of a CT salt of the EDT-TTF moiety with F4TCNQ on the surface of SM-ITO. ${ }^{16}$

The SM-ITO and bare ITO glasses were used as a working electrode to measure the $\mathrm{CV}$ in a $\mathrm{CH}_{2} \mathrm{Cl}_{2}$ solution with or without F4TCNQ (Fig. 5). CV using an SM-ITO electrode (Fig. 5D) shows the first anodic potential $\left(E_{\mathrm{pa}}{ }^{1}\right)$ at $0.672 \mathrm{~V}$, which corresponds to the oxidation process of [EDT-TTF $]^{\circ+} \leftarrow$ [EDT$\mathrm{TTF}]^{0}$. This value is actually very close to the first cathodic potential of F4TCNQ $\left(E_{\mathrm{pc}}{ }^{2}=0.625 \mathrm{~V}\right)$, which corresponds to the reduction process of $[\mathrm{F} 4 \mathrm{TCNQ}]^{--} \leftarrow[\mathrm{F} 4 \mathrm{TCNQ}]^{0}$, as mea- 


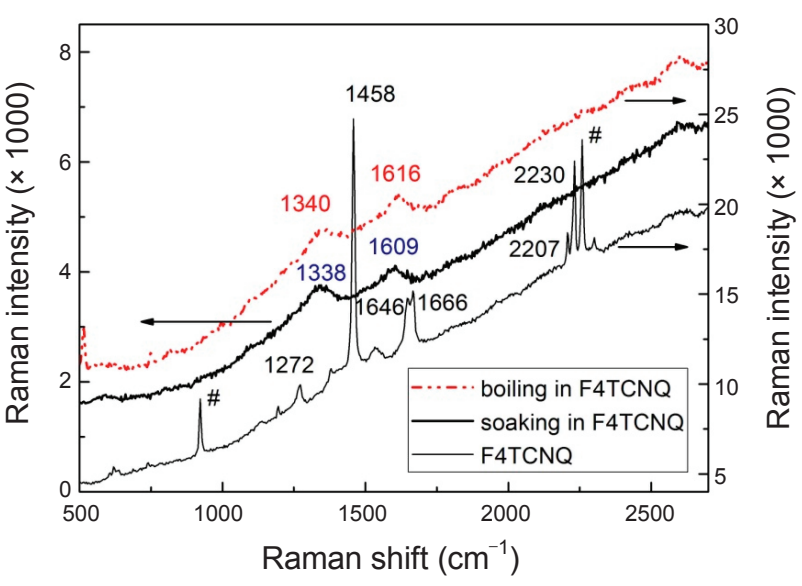

Figure 4. The Raman spectra of F4TCNQ dissolved in $\mathrm{CH}_{3} \mathrm{CN}$ (lower), and SAM of [EDT-TTF]/[F4TCNQ] CT salt generated by soaking (middle) and boiling (upper). Solvent peaks are denoted by \#.

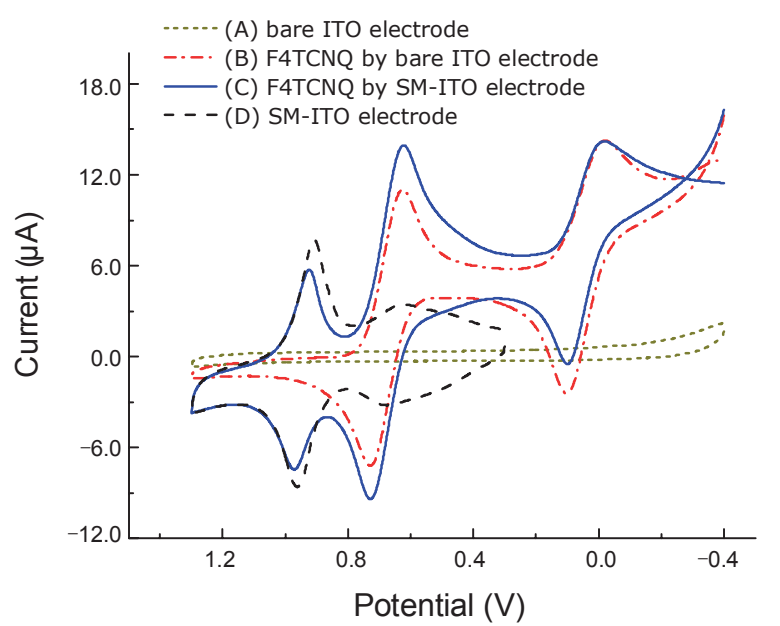

Figure 5. The cyclic voltammograms (vs. $\mathrm{Ag} / \mathrm{AgCl})$ obtained using bare ITO and SM-ITO electrodes $\left(\mathrm{Fc} / \mathrm{Fc}^{+}=0.585 \mathrm{~V}\right)$ in a $\mathrm{CH}_{2} \mathrm{Cl}_{2}$ solution with or without F4TCNQ.

sured with a bare ITO electrode (Fig. 5B). This coincidence of the redox potentials is thought to facilitate the charge-transfer process between the EDT-TTF moiety in SAM and F4TCNQ in solution. It is obviously comparable with the $\mathrm{CV}$ results of TCNQ ${ }^{8}$ in which the first cathodic potential $\left(E_{\mathrm{pc}}{ }^{2}=0.304 \mathrm{~V}\right)$ for the reduction process of [TCNQ $]^{--} \leftarrow$ TCNQ $^{0}$ is much lower than the first anodic potential $\left(E_{\mathrm{pa}}{ }^{1}=0.672 \mathrm{~V}\right)$ of the EDT-TTF moiety. Moreover, the current intensity of the second redox process of EDT-TTF moiety $\left(i_{2}(\mathrm{EDT}-\mathrm{TTF})\right)$ is significantly weaker than that of TCNQ $\left(i_{2}\right.$ (TCNQ)). ${ }^{8}$ On the other hand, the intensity of $i_{2}$ (EDT-TTF) $(\sim 6 \mu \mathrm{A})$ in this research is significant with respect to that of $i_{2}(\mathrm{~F} 4 \mathrm{TCNQ})$, that is, a half of $i_{2}$ (F4TCNQ) as shown in Fig. 5C.

In conclusion, an EDT-TTF derivative with a decylphosphonic acid moiety was synthesized and utilized in the preparation of a surface-modified ITO (SM-ITO) electrode. The EDT-TTF moiety in SM-ITO forms a charge-transfer (CT) complex by boiling, or even soaking, in a $\mathrm{CH}_{2} \mathrm{Cl}_{2}$ solution of F4TCNQ, which is confirmed by the depression of CV cycles corresponding to $[\mathrm{EDT}-\mathrm{TTF}]^{\bullet+/ 0}$ and $[\mathrm{EDT}-\mathrm{TTF}]^{2+/ \bullet+}$ processes. Further evidence was given by micro-Raman spectra, in which the $\mathrm{C}=\mathrm{C}$ ring stretching $\left(v_{2} 1665 \mathrm{~cm}^{-1}\right)$ and external stretching $\left(v_{3} 1456 \mathrm{~cm}^{-1}\right)$ vibrations of F4TCNQ shift to 1616 and $1340 \mathrm{~cm}^{-1}$ for a boiled SM-ITO, indicating the formation of an [EDT-TTF]/ [F4TCNQ] CT complex. The CV of F4TCNQ measured with an SM-ITO working electrode shows that $E_{\mathrm{pa}}{ }^{1}(0.672 \mathrm{~V})$, corresponding to the [EDT-TTF] $]^{+/ 0}$ process is very close to $E_{\mathrm{pc}}{ }^{2}$ $(0.625 \mathrm{~V})$, corresponding to [F4TCNQ] $]^{-/ 0}$ process. This observation implies the facile formation of the F4TCNQ CT salt of the EDT-TTF moiety, compared to TCNQ CT complex, even by soaking at room temperature.

Acknowledgments. This work was supported by the National Research Foundation of Korea Grant funded by the Korean Government (KRF-2008-314-C00190 and STAR Program 20082010). We gratefully appreciate Dr. M. Fourmigue (CNRS-Univ. of Rennes 1, France) for the supply of F4TCNQ compound.

Supporting Information Available. $\operatorname{COSY}\left({ }^{1} \mathrm{H}-{ }^{1} \mathrm{H}\right)$ and $\mathrm{HSQC}$ $\left({ }^{13} \mathrm{C}-\mathrm{H}\right)$ spectra of compound $(5)$ are available on request from the corresponding author.

\section{References}

1. Yamada, J.; Sugimoto, T. TTF Chemistry; Springer: Kodansha, 2004.

2. Ferraris, J.; Cowan, D. O.; Walatka, V. V.; Perlstein, J. H. J. Am. Chem. Soc. 1973, 93, 948.

3. Farges, J. P., Ed.; Organic Conductors: Fundamentals and Applications; Marcel Dekker: NY, 1994.

4. Talham, D. R. Chem. Rev. 2004, 104, 5479.

5. Ulman, A. Chem. Rev. 1996, 96, 1533.

6. (a) Petruska, M. A.; Watson, B. C.; Meisel, M. W.; Talham, D. R. Chem. Mater. 2002, 14, 2011. (b) Zheng, S.; Barlow, S.; Parker, T. C.; Marder, S. R. Tetrahedron Lett. 2003, 44, 7989. (c) Yip, C. M.; Ward, M. D. Langmuir 1994, 10, 549.

7. Noh, D. Y.; Willing, G. A.; Han, C. Y.; Shin, K. S.; Geiser, U.; Wang, H. H. Chem. Mater. 2004, 16, 4777.

8. Kim, J. S.; Choi, K.; Lee, H.; Noh, D. Y.; Lee, H. J. Colloids and Surface A: Physicochem. Eng. Aspects 2008, 313-314, 625.

9. Shin, K. S.; Son, K. I.; Kim, J. I.; Hong, C. S.; Suh, M.; Noh, D. Y. Dalton Trans. 2009, 1767.

10. (a) Savignac, P.; Iorga, B. Modern Phosphonate Chemistry; CRC Press: 2003. (b) Katz, H. E.; Bent, S. F.; Wilson, W. L.; Schiling, M. L.; Ungashe, S. B. J. Am. Chem. Soc. 1994, 116, 6631. (c) Kartz, H. E.; Wilson, W. L.; Scheller, G. J. Am. Chem. Soc. 1994, 116, 6636.

11. (a) Wang, C.; Batsanov, A. S.; Bryce, M. R.; Howard, J. A. K. Synthesis 1998, 1615. (b) Steimecke, G.; Sieler, H. J.; Kirmse, R.; Hoyer, E. Phosphorus and Sulfur 1979, 7, 49. (c) Varma, K. S.; Bury, A.; Harris, N. J.; Underhill, A. E. Synthesis 1987, 837. (d) Jia, C.; Zhang, D.; Xu, W.; Zhu, D. Org. Lett. 2001, 3, 1941.

12. (a) Hanson, E. L.; Schwartz, J.; Nickel, B.; Koch, N.; Danisman, M. F. J. Am. Chem. Soc. 2003, 125, 16074. (b) Srinivasan, G.; Pursch, M.; Sanders, L. C.; Muller, K. Langmuir 2004, 20, 1746.

13. (a) Yokota, Y.; Yuge, R.; Miyazaki, A.; Enoki, T.; Hara, M. Mol. Cryst. Liq. Cryst. 2003, 407, 121. (b) Kozlov, M. E.; Pokhodnia, K. I.; Yurchenko, A. A. Spectrochim. Acta 1987, 27A, 323.

14. Brewer, S. H.; Brown, D. A.; Franzen, S. Langmuir 2002, 18, 6857.

15. Yuge, R.; Miyazaki, A.; Enoki, T.; Tamada, K.; Nakamura, F.; Hara, M. J. Phys. Chem. B 2002, 106, 6894.

16. (a) Meneghetti, M.; Toffoletti, A. Synth. Met. 1999, 103, 2318. (b) Meneghetti, M.; Bozio, R.; Pecile, C. Synth. Met. 1987, 19, 451. 